\title{
ensinar pelo falso e pelo crime uma proposta em Educação da Cultura Visual a partir de arte falsificada 1 \\ Emilio Caetano Ferreira
}

Introdução

As obras de arte consagradas ou produzidas por artistas célebres trazem em torno de si uma aura de objeto único, um aspecto místico, um fetiche mágico e quando, ocasionalmente, se descobre que

1

Este artigo apresenta, de forma modificada, o pré-projeto de pesquisa submetido para seleção de candidatos para o Mestrado Acadêmico em Arte na linha de pesquisa Educação em Artes Visuais do Programa de Pós-Graduação em Arte do Departamento de Artes Visuais da Universidade de Brasília. 
qualquer uma é falsa, sua aura de certa forma se desfaz e escorre pelos dedos. É a partir desse fenômeno que este projeto tem como proposta abordar pedagogicamente com uma turma de estudantes do ensino médio da rede pública do Distrito Federal o campo artístico e suas relações, utilizando como propulsor o exemplo dos falsários e obras de arte falsas, bem como reflexões sobre como o mercado e o campo artístico reagem a isso.

Em contrapartida, a cultura popular coleciona diversas produções cujos enredos abordam o tema da falsificação e dos falsificadores de arte seja em filmes, séries, novelas ou em livros. Esse enredo desperta a curiosidade e alimenta o imaginário do público que vê com interesse o fato de alguém poder reproduzir algo com precisão ou astúcia suficiente para enganar especialistas. É com esse possível interesse que este projeto conta para propor e realizar uma ação educativa abordando o campo da arte e seu mercado (de bens simbólicos e/ou físicos) e do caso do falsificador Wolfgang Beltracchi.

Justificativa

Considere-se momentaneamente um estudante do ensino regular no Distrito Federal e - de acordo com o Currículo em Movimento do Distrito Federal - que estudaria de modo predominante a história da arte e os diversos estilos artísticos (Distrito Federal, 2016). Foi a partir da vivência cotidiana com esse currículo, tendo-o como referência de trabalho nos últimos anos, que surgiram inquietações a respeito de como abordar a história da arte com os estudantes sem cair em simplificações, sem apenas referendar o conteúdo de modo acrítico, indo além do conteúdo formal e do estudo passivo de biografias e obras de referência.

Posto isso e apresentando a questão das obras de arte falsificadas percebe-se que elas colocam em xeque não apenas as crenças e valores do campo artístico como também o próprio fazer pedagógico relacionado a objetos considerados artísticos. Ao apresentar de forma naturalizante os grandes artistas e as obras consagradas em sala de aula, desvinculado do conhecimento de que são produtos culturais e históricos e de que esses valores podem mudar, o professor corre alguns riscos. Por exemplo: ele aprecia com os estudantes a produção artística e seus valores estéticos, a biografia do artista, seu contexto histórico, organiza uma excursão ao museu, mas... e se a obra for falsa?

Propõe-se então que os estudantes tenham acesso a informações que possam constituir um mirante de onde possam observar as regras do jogo da arte para que possam percebê-la como uma construção social, onde os objetos são hierarquizados culturalmente (DIKOVITSKAYA, 2010). Um 
mirante em que os estudantes possam observar a arte e a si mesmos percebendo o lugar onde estão inseridos nessas relações, um lugar em que ao confrontar o mundo da arte com produções de arte falsas, possa se levantar questões: $O$ que é uma obra de arte? O que faz a originalidade de um autor? Por que uma obra de arte falsa antes louvada perde seus valores ao se descobrir falsa? Por que a crítica tem o poder de fazer e desfazer obras de arte? Ou, para dizer do modo arrojado proposto por Nelson Goodman "a verdadeira questão não é "Quais os objetos que são (permanentemente) obras de arte?" mas "Quando é que um objeto é uma obra de arte?" - ou mais brevemente, [...] "Quando é arte?»" (GOODMAN, 1995: 113). Essas questões são relevantes de se realizar já que mesmo em tempos de pós-modernidade continua-se dependente de categorias sempre cultivadas na modernidade como

categorias do novo, que não podem ser totalmente erradicadas do 'novo' sistema, seja qual for sua retórica. $E$ isso, na verdade, é uma contradição nada menor, ou insignificante, para a pósmodernidade, incapaz de se desfazer do valor supremo da inovação (apesar do fim do estilo e da morte do sujeito), [...] porque os museus e as galerias de arte dificilmente podem funcionar sem ela (JAMENSON, 2005: 13).

Apresentar aos estudantes a questão das obras de arte falsas é possibilitar construir um vislumbre de como funciona o campo artístico e como são construídas culturalmente e historicamente as narrativas e categorias tradicionais como essa que criam e legitimam os grandes artistas e as grandes obras de arte. Ao mesmo tempo a proposta permite reflexões sobre a prática pedagógica relacionada com essas visualidades e seus processos de produção, recepção e consumo, a partir do entendimento da educação da cultura visual como uma

concepção pedagógica que destaca as múltiplas representações visuais do cotidiano como elementos centrais que estimulam práticas de produção, apreciação e crítica de artes e que desenvolvem cognição, imaginação, consciência social e sentimento de justiça (DIAS, 2011 : 54).

Parece claro que os jovens estudantes em geral, em suas vidas fora da escola, não consomem a chamada "arte culta" e realizem suas experiências vitais através da cultura de massa, sendo que somente em situações onde a arte ou os artistas se tornaram ícones da cultura de massa é que eles Ihes dão uma atenção mínima (FREEDMAN, 2006; AGUIRRE, 2009). Apesar disso entende-se que seja importante que os jovens estudantes possuam informações sobre arte e entendam de modo crítico o campo da arte e seu funcionamento. Primeiro porque esse conhecimento é visto como "senha" que denota uma posição social tida como superior econômica, mas principalmente intelectualmente (COLI, 1995; BOURDIEU \& PASSERON, 1975; TAYLOR, 2005) e conhecer seu modo de produção e consumo permite observar essas relações de modo crítico; segundo porque os 
estudantes, como integrantes de um sistema democrático, possuem o direito a esse conhecimento que permeia as decisões das políticas culturais do país e como cidadãos contribuintes de impostos serão eles que arcarão com as despesas dos patrocínios culturais do estado às instituições como museus, pinacotecas, incentivos a artistas e toda sorte de eventos culturais relacionados com a arte (TAYLOR, 2005).

O projeto é pensado para estudantes do ensino médio por já terem tido - considerando o Currículo em Movimento seguido pela rede de educação pública do Distrito Federal - algum contato com o conteúdo da história da arte em séries anteriores, sendo assim é possível re-olhar esse conteúdo sob um ponto de vista crítico. Por fim, o fato de Wolfgang Beltracchi ser o foco entre os casos de falsificações para a construção do projeto educativo decorre das seguintes razões (sem ordem de relevância): é um caso recente e com bons materiais disponíveis sobre o caso; é um caso onde se podem observar claramente os discursos que circundam os artefatos artísticos para sua legitimação (BIRKENSTOCK, 2014).

\section{$\underline{\text { Objetivo }}$}

Tem-se por objetivo fundamentar, elaborar e executar/refletir uma proposta em Educação da Cultura Visual a partir da falsificação de arte, especialmente no caso de Wolfgang Beltracchi. A proposta a partir das obras de arte falsificadas permite refletir sobre as regras, ritos, crenças e processos de legitimação e consagração de artistas e obras de arte juntamente com estudantes do ensino médio da educação pública do Distrito Federal.

\section{Revisão da Literatura}

Para que se perceba claramente como os artefatos falsificados causam alvoroço ou desafiam as crenças e valores do meio artístico e suas implicações na educação é desejável conhecer como as ideias de autenticidade e valoração da individualidade do artista - tão caras ao mercado de arte - foram constituídas. Essas ideias progrediram substancialmente quando "a partir das últimas décadas do século XIX o termo "arte” ganhou sentido ideológico vinculado a uma produção material individualizada, superior, que pretendia transcender a experiência comum" (MARTINS, 2008: 27).

Antes disso os critérios de originalidade das produções visuais eram difusos, confusos e muitas vezes irrelevantes posto que 
Com efeito, o caráter único da obra de arte só começou a ter expressão a partir do Romantismo; em épocas anteriores não se distinguiam com precisão original e cópia, pela própria maneira de realização do trabalho artístico em ateliês em que colaboravam, o mestre e seus discípulos (ROJAS, 1979: 51).

Claro que aqui e acolá encontramos traços individualistas aparecem e desaparecem na incessante produção cultural humana. Em alguns momentos na Grécia Antiga, por exemplo, entre os séculos $V$ e IV a.c. "a aspiração a conservar a propriedade espiritual [...] são um sinal dos tempos; nós o encontramos também nas artes plásticas, pois os escultores e pintores de vasos escreviam o nome nas suas obras" (JAEGER, 2001: 235). Apesar disso o que encontramos, de modo geral, em tempos que antecedem ○ Romantismo são as produções divulgadas e modificadas, recriadas e atribuídas de modo apócrifo a determinados autores sem uma preocupação fanática com a autenticidade. É com o processo de autonomização do campo artístico que os valores da autenticidade, superioridade e culto à personalidade do artista ganham espaço. Essa autonomia foi conquistada gradualmente

\begin{abstract}
Tendo início na Florença do século XV, com a afirmação de uma legitimidade propriamente artística, ou seja, do direito dos artistas legislarem com exclusividade em seu próprio campo - o campo da forma e do estilo -, ignorando exigências externas de uma demanda social subordinada a interesses religiosos ou políticos [...] (BOURDIEU, 2011: 101).
\end{abstract}

A partir do momento em que o campo artístico se torna cada vez mais autônomo e constitui suas próprias crenças, princípios e maneiras particulares de legitimação, reforça-se cada vez mais a “ideologia 'carismática' da criação" que "dirige o olhar para o produtor aparente - pintor, compositor, escritor -, impedindo que se pergunte quem criou esse 'criador' e o poder mágico de transubstanciação de que é dotado" (BOURDIEU, 1996: 193). É essa fé no "criador"

que geralmente é trabalhada nas escolas, através das biografias dos artistas, o contato com suas obras e sua classificação estilística, informações que são repassadas aos estudantes sem a contextualização da formação da arte como categoria ou campo específico, celebrando a personalidade do artista e ocultando que o poder do "criador" celebrado decorre do espaço de jogo que progressivamente se instituiu. $\mathrm{E}$ se os professores de arte são os responsáveis pela "produção de consumidores aptos a reconhecer a obra de arte como tal" por serem "responsáveis pela insinuação inicial das disposições artísticas" (BOURDIEU, 1996, p. 259) é preciso ir além e trabalhar com o pensamento de que a "Arte Educação deve ajudar os estudantes a conhecerem as artes visuais na sua integridade e complexidade, seus conflitos de ideias como também seus objetos legitimados, e suas conexões com o pensamento social" já que "reproduzir construções limitadas de conhecer não deve ser uma proposta do ensino de arte contemporâneo" (STUHR \& FREEDMAN, 2009: 17, tradução nossa).

Muitas vezes se percebe que os valores atribuídos às produções artísticas e que se consolidaram culturalmente e historicamente são muitas vezes levados para os estudantes de modo naturalizante, 
como se fossem verdades evidentes - os grandes artistas, as grandes obras de arte, a genialidade - e, no entanto, são um construto cultural e histórico. A tarefa do educador passa então pelo problema de levar aos estudantes uma compreensão de como o campo artístico se desenvolveu para que tenham uma compreensão clara de como e o porquê dos valores que fazem de determinados autores e artefatos os grandes artistas e as grandes obras apresentados atualmente na escola e nas produções midiáticas em geral, ou seja,

O desafio educativo de ensinar a cultura visual do passado não consiste simplesmente em ensinar história da arte, mas sim que se trata de uma questão mais ampla de ajudar os alunos a desenvolver uma compreensão da rica vida social da cultura visual (FREEDMAN, 2006: 73, tradução nossa).

Portanto educadores devem estar equipados para a prática de uma pedagogia dos objetos culturais de modo que o trabalho pedagógico revele a maneira como são constituídos, como objetos que adquirem sua relevância por meio de sua relação com instituições sociais, recursos e práticas não-discursivas (GIROUX, 2003). A cultura visual é um campo que permite aos educadores equiparem-se para tal tarefa ao tornar-lhes disponíveis algumas estratégias valiosas para lidar com a produção visual, visto que

A cultura visual se interessa pelos acontecimentos visuais em que o consumidor busca a informação, 0 significado ou o prazer conectados com a tecnologia visual. Entendo por tecnologia visual qualquer forma de aparato produzido que seja para ser observado ou para aumentar a visão natural, desde a pintura à óleo até a televisão e a Internet (MIRZOEFF, 2003: 19, tradução nossa).

Ao tomar o exemplo da arte falsa em uma proposta de educação em cultura visual apropria-se da tomada de posição da cultura visual em prol de uma transformação do modo de encarar a história da arte e seus produtos e "nesse processo de transformação, arte educadores estão substituindo antigos olhares do currículo e ensino com uma expansão da visão do lugar das artes visuais na experiência humana" (STUHR \& FREEDMAN, 2009: 9, tradução nossa). Transformar o modo de encarar a história da arte e o currículo é essencial para deslocar o foco de uma educação baseada em ver a história da arte a partir de análises estéticas que a percebem como um desencadeamento natural de estilos e artistas abordados muitas vezes a partir de análises formais e biográficas. Apresentar então aos estudantes a questão da arte falsificada permite-se mudar $\circ$ foco do currículo, e "o foco do currículo muda se os estudantes estão desenvolvendo uma compreensão da complexidade do pensamento relacionado às imagens visuais e artefatos" (STUHR \& FREEDMAN, 2009: 16, tradução nossa). Promover uma mudança de foco e propor um olhar para a história da arte pelo prisma das falsificações possibilita pensar a arte para além da linguagem, de seu conteúdo formal, e 
isso não significa abandonar a ideia de arte como linguagem, mas buscar, no caráter concreto da vida social, neste mundo espetacularizado, saturado de mensagens e informações visuais, sonoras, gestuais, orais, outras metáforas/modelos para pensar a arte ou, melhor dizendo, a cultura estética [...]. Precisamos investigar os limites da ideia de arte como linguagem, guardando suas possibilidades, mas indicando outras direções para nosso pensamento (TOURINHO, 2009: 55).

Concluindo, indicar outras direções para o nosso pensamento não implica em abolir ou negar o conteúdo da história da arte, mas abordá-lo de um ponto de vista crítico, que empodere os estudantes de conhecimentos capazes de compreender que a arte, sendo parte da cultura visual é assim como esta "uma «construção social», que é aprendida e cultivada, não simplesmente dada pela natureza; que, por consequência, teria uma história relacionada [...] com a história da arte, as tecnologias, as mídias, e as práticas sociais de representação e recepção" (MITCHELL, 2016: 19, tradução nossa). Desse modo, reside aí a preocupação em propor a abordagem de obras falsas e falsificadores: desnaturalizar o olhar e colocar em debate as tramas da construção social e cultural da arte.

\section{Procedimentos Metodológicos}

A partir do objetivo de fundamentar, elaborar e executar/refletir uma proposta em Educação da Cultura Visual a partir da falsificação de arte este projeto possui seus procedimentos metodológicos planejados e organizados da seguinte maneira:

(1) Fundamentar: Os Estudos da Cultura Visual independentemente do que os teóricos da área consideram como seu objeto de estudo - ou seja, o que delimitam como cultura visual - ou da nomenclatura para o campo de estudo - se Estudos visuais ou Cultura visual - possuem todos eles a noção de que se trata de estudos realizados de modo interdisciplinar (FREEDMAN, 2003; MIRZOEFF, 2003; MITCHELL, 2003; HERNÁNDEZ, 2007; DIAS, 2011). Desse modo, a fundamentação do trabalho ocorrerá recorrendo-se a diálogos com outras áreas além dos autores da cultura visual como a sociologia da arte, história da arte, estudos culturais e filosofia de acordo com o que a demanda da tarefa de refletir sobre o assunto for exigindo como ferramentas. Para isso será feito um levantamento bibliográfico tanto para buscar o que se ignora (ECO, 2003) quanto para aprofundar o tema ao se explorar, selecionar, analisar e interpretar os textos (GIL, 2010). A fundamentação construirá a ponte entre o tema da falsificação em arte e uma prática pedagógica sobre esse tema e suas implicações no campo da arte e na educação, sempre procurando "levar à educação contribuições vinculadas aos Estudos da Cultura Visual" (HERNÁNDEZ, 2007: 18). 


\section{$\underline{\text { Referencial Teórico }}$}

AGUIRRE, Imanol. Imaginando um futuro para a educação artística. In: MARTINS, Raimundo; TOURINHO, Irene (Orgs.). Educação da cultura visual: Narrativas de ensino e pesquisa. Santa Maria: Editora da UFSM, 2009.

BIRKENSTOCK, Arne. Beltracchi - A Arte da Falsificação. 2014.

BOURDIEU, Pierre; PASSERON, Jean Claude. A reprodução: elementos para uma teoria do sistema de ensino. Rio de Janeiro: Francisco Alves, 1975.

BOURDIEU, Pierre. As Regras da Arte. Gênese e estrutura do campo literário. São Paulo, Companhia das Letras, 1996. A Economia das Trocas Simbólicas. São Paulo, Perspectiva, 2011.

COLI, Jorge. O que é arte? São Paulo, Editora Brasiliense, 1995. DIAS, Belidson. O I/Mundo da Educação em Cultura Visual. Brasília, Editora da pós-graduação em arte da Universidade de Brasília, 2011.

DIKOVITSKAYA, Margaret. A look at visual studies. Disponível em: $<<$ http://chin.nju.edu.cn/zwx/zhouxian/shijue/ chapter 1/2.doc $>$ >. Acesso em abril de 2010.

DISTRITO FEDERAL. Currículo em Movimento.

ECO, Umberto. Como se faz uma tese. São Paulo, Editora Perspectiva, 2003.

FREEDMAN, Kerry. Enseñar la Cultura Visual. Barcelona, Octaedro, 2006.

GIL, Antonio Carlos. Como elaborar projetos de pesquisa. São Paulo, Atlas, 2010.

GOODMAN, Nelson. Modos de Fazer Mundos. Lisboa, Edições Asa, 1995.

GIROUX, Henry. Atos Impuros: A prática política dos estudos culturais. Porto Alegre, Artmed, 2003.

HERNÁNDEZ, Fernando. Catadores da Cultura Visual: transformando fragmentos em nova narrativa educacional. Porto Alegre, Mediação, 2007.

JAEGER, Werner. Paidéia: A formação do Homem Grego. São Paulo, Martins Fontes, 2001.

JAMENSON, Frederic. Modernidade Singular. Rio de Janeiro, Civilização Brasileira, 2005.

MARTINS, Raimundo. Das belas artes à cultura visual: enfoques e deslocamentos. In: Visualidade e Educação. Goiânia, FUNAPE, 2008, p. 25-35.

MIRZOEFF, Nicholas. Una Introducción a la Cultura Visual. Barcelona, Paidós, 2003.

MITCHELL, W.J.T. Mostrando el ver. In: Estudios Visuales, Murcia - España, num. 1, p 17-40, 2003. Disponível em: <<http://www.estudiosvisuales.net/revista/pdf/num 1/mitchell.pdf >> Acesso em março

de 2010. ROJAS, Roberto. O laboratório dos museus. Identificações e falsificações. In: O

Mundo dos Museus. Navarra, Gráficas Estella, 1979, p. 50-68.

STUHR, Patricia, \& FREEDMAN, Kerry. Curriculum change for the 21 st th: visual culture in art education. In: Revista do Programa de Pós-Graduação em Arte. Brasília, Editora Brasil, V.8, n.1, Janeiro/junho de 2009. 
METAgraphias: letra E (sobre errância e-Rancièrráticas) v.2 n.2 junho| 2017 ensinar pelo falso e pelo crime•Emilio Caetano Ferreira (emiliovertigo@hotmail.com)

TAYLOR, Roger. Arte, Inimiga do Povo. São Paulo, Conrad Editora do Brasil, 2005.

TOURINHO, Irene. Currículo para além das grades: de porões a terraços, praças e jardins... In: Revista do Programa de Pós-Graduação em Arte. Brasília, Editora Brasil, V. 8, n. 1, janeiro/junho de 2009. 